\section{Altered alkaline phosphatase activity in obese Zucker rats liver respect to lean Zucker and Wistar rats discussed in terms of all putative roles ascribed to the enzyme}

\author{
V. Bertone, ${ }^{1}$ E. Tarantola, ${ }^{1}$ A. Ferrigno, ${ }^{2}$ \\ E. Gringeri, ${ }^{3}$ S. Barni, ${ }^{1}$ M. Vairetti, ${ }^{2}$ \\ I. Freitas ${ }^{1}$ \\ 'Department of Animal Biology and \\ Histochemistry and Cytometry, Section \\ IGM-CNR, University of Pavia, Italy; \\ ${ }^{2}$ Department of Internal Medicine and \\ Therapeutics, University of Pavia, Italy; \\ ${ }^{3}$ Department of Surgical and \\ Gastroenterological Sciences P.G. Cevese, \\ University of Padua, Italy
}

\section{Abstract}

Biliary complications often lead to acute and chronic liver injury after orthotopic liver transplantation (OLT). Bile composition and secretion depend on the integrated action of all the components of the biliary tree, starting from hepatocytes. Fatty livers are often discarded as grafts for OLT, since they are extremely vulnerable to conventional cold storage (CS). However, the insufficiency of donors has stimulated research to improve the usage of such marginal organs as well as grafts. Our group has recently developed a machine perfusion system at subnormothermic temperature $\left(20^{\circ} \mathrm{C}\right.$; MP20) that allows a marked improvement in preservation of fatty and even of normal rat livers as compared with $\mathrm{CS}$. We sought to evaluate the response of the biliary tree of fatty liver to MP20, and a suitable marker was essential to this purpose. Alkaline phosphatase (AlkP, EC 3.1.3.1), frequently used as marker of membrane transport in hepatocytes and bile ducts, was our first choice. Since no histochemical data were available on AlkP distribution and activity in fatty liver, we have first settled to investigate AlkP activity in the steatotic liver of fatty Zucker rats ( $f a / f a$ ), using as controls lean Zucker ( $f a /+)$ and normal Wistar rats. The AlkP reaction in Wistar rats was in accordance with the existing data and, in particular, was present in bile canaliculi of hepatocytes in the periportal region and midzone, in the canals of Hering and in small bile ducts but not in large bile ducts. In lean ZR liver the AlkP reaction in Hering canals and small bile ducts was similar to Wistar rat liver but hepatocytes had lower canalicular activity and besides presented moderate basolateral reac- tion. The difference between lean Zucker and Wistar rats, both phenotypically normal animals, could be related to the fact that lean Zucker rats are genotypically heterozygous for a recessive mutated allele. In fatty liver, the activity in ductules and small bile ducts was unchanged, but most hepatocytes were devoid of AlkP activity with the exception of clusters of macrosteatotic hepatocytes in the mid-zone, where the reaction was intense in basolateral domains and in distorted canaliculi, a typical pattern of cholestasis. The interpretation of these data was hindered by the fact that the physiological role of AlkP is still under debate. In the present study, the various functions proposed for the role of the enzyme in bile canaliculi and in cholangiocytes are reviewed. Independently of the AlkP role, our data suggest that AlkP does not seem to be a reliable marker to study the initial step of bile production during OLT of fatty livers, but may still be used to investigate the behaviour of bile ductules and small bile ducts.

\section{Introduction}

The increased demand of organs for orthotopic liver transplantation (OLT) has stimulated the research of strategies to increase the pool of donors by including the so-called marginal organs, especially fatty livers. Liver steatosis, which is frequently observed in potential donors, has been considered an important risk factor for injury caused by conventional cold storage with a higher incidence of postoperative primary non-function and poor initial function of the graft, and lower patient and graft survival..$^{1-3}$ As a matter of fact, steatotic livers are more susceptible to ischemia/reperfusion injury after transplantation, with loss of viability of sinusoidal endothelial cells, sinusoidal congestion and rupture of hepatocytes releasing fat droplets, causing microcirculatory failure. ${ }^{4-8}$

Biliary complications are considered the Achilles' heel of liver transplantation because of their frequency and potential lethal effect on the survival of both graft and patient. ${ }^{9-11}$ These complications are a major cause of morbidity and graft failure in patients after OLT and include a wide spectrum of functional and anatomical abnormalities, such as bile leakage and large biliary duct strictures; their incidence is estimated to be $8-20 \%$ and may lead to acute and chronic liver injury. ${ }^{2-14}$ The fast restoration of biliary secretion is an important index of hepatic functional restoration after preservation by cold ischemic storage (CS), ${ }^{15}$ and bile analysis is a useful tool to assess the integrity of biliary epithelial cells after cold ischemia/reperfusion of rat liver. ${ }^{16}$ The forma-
Correspondence: Prof. Isabel Freitas, Laboratory of Comparative Anatomy and Cytology, Department of Animal Biology, Palazzo Botta 2, via Ferrata 9, 27100 Pavia, Italy.

Tel. +39.0382.986317 - Fax: +39.0382.986406.

E-mail: freitas@unipv.it

Key words: biliary tract, alkaline phosphatase, fatty liver, cholestasis, bile canaliculi, hepatocytes, cholangiocytes.

Acknowledgements: the authors thank Mr. Gaetano Viani for his skilful technical assistance. This research was supported by MIUR-PRIN (Ministero dell'Università e Ricerca, Progetti di Rilevante Interesse Nazionale) 2004 and 2006 and by F.A.R. (Fondi di Ateneo per la Ricerca), University of Pavia, Italy.

Received for publication: 13 December 2010. Accepted for publication: 18 December 2010.

This work is licensed under a Creative Commons Attribution 3.0 License (by-nc 3.0).

(C) Copyright V. Bertone et al., 2011

Licensee PAGEPress, Italy

European Journal of Histochemistry 2011; 55:e5 doi:10.4081/ejh.2011.e5

tion of bile depends on the structural and functional integrity of the biliary tree and its impairment results in the syndrome of cholestasis.

Experimental and clinical studies have indicated that bile formation early after liver transplantation may be disturbed, resulting in more cytotoxic bile with a relatively low phospholipids/bile salt ratio. ${ }^{7}$ A close relationship between this ratio early after liver transplantation and injury of the small bile ducts in the liver has been found, ${ }^{18}$ supporting the hypothesis that early changes in bile composition contribute to the relatively late stricturing of the large bile ducts. ${ }^{14}$ This data suggest that the different cell types of the biliary tree (hepatocytes, transition cells of Hering canals and cholangiocytes in small and large bile ducts) play different roles in the progressive post-transplantation injury phases to the biliary tract.

The analysis of the biliary tree behaviour towards transplantation has however lagged behind studies concerning hepatocytes and sinusoidal cells, even though bile canaliculi are one of the liver structures that are damaged markedly and early during ischemiareperfusion occurring in patients undergoing 0LT. ${ }^{19}$ Furthermore, the damage to bile duct cells is important in the long-lasting phase of reperfusion injury, ${ }^{20}$ the recovery of the biliary tree from preservation injury takes longer compared with hepatocytes or endothelial cells $^{21}$ and regeneration of its cellular ATP is 
much slower than in hepatocytes.22 Even less is known, to the best of our knowledge, on the behaviour of the biliary structures of fatty livers respect to OLT.

Most animal studies showing increased susceptibility or decreased tolerance of fatty livers to injury have been conducted in genetically obese rodents such as the obese Zucker rat (ZR). ${ }^{23-25}$ The obese ZR are homozygous for non-functional leptin receptors ( $f a / f a) ;{ }^{26}$ they thus cannot respond to the satiety stimulus and became hyperphagic, obese, hyperinsulinemic (insulin-resistant), but have normal blood glucose levels and do not develop diabetes. $^{24}$ The lean ZR that are heterozygous for the allele fa $(f a /+)$ maintain a lean phenotype throughout life with normal blood insulin and glucose levels.

Our group has recently developed a machine perfusion (MP) system at subnormothermic temperature, $20^{\circ} \mathrm{C}$ (MP20) with a low-viscosity perfusion medium based on Krebs-Henseleit buffer and containing $\mathrm{N}$-acetylcysteine, glucose and low concentration of calcium, that appears as a promising strategy to protect the liver of normal rats (Wistar, lean Zucker) and fatty liver (FL) of obese ZR performing biochemical, histochemical and ultrastuctural analyses. ${ }^{27,28}$ In particular, we have shown that, compared with traditional cold storage, MP20 leads to FL preservation in terms of enzyme release into the perfusate and bile, energy charge, glycogen stores and reactive oxygen species production. ${ }^{28}$ Histochemical analyses revealed that MP20 caused a marked reduction of steatosis through ketogenesis (preliminary results) ${ }^{29}$ and of parenchymal and sinusoidal cell death by apoptosis (preliminary results). ${ }^{30}$ In order to further the research to the biliary tract, reliable markers of the biliary tree of fatty liver were necessary.

The first candidate enzyme was alkaline phosphatase (AlkP) (orthophosphoricmonoester phosphohydrolase; EC 3.1.3.1), a metalloprotein bound to the outer leaflet of the plasma membrane through a glycosylphosphatidylinositol (GPI) anchor, markedly expressed in the apical pole of hepatocytes and cholangiocytes and secreted in bile in large amounts $^{31-33}$ that is frequently used as marker of membrane transport in hepatocytes and bile ducts. The determination of AlkP in the bile is used as an index of damage to cholangiocytes. ${ }^{34}$ Since no data were available concerning this enzyme in fatty liver, we investigated AlkP activity and its distribution in the liver of obese ZR, frequently used as models of obesity and insulin-resistance. As controls, we used either lean Zucker rats (the usual control for obese Zucker rats), heterozygous for the mutated allele $(f a /+)$ and normal Wistar rats that do not present the mutation.

\section{Materials and Methods}

\section{Chemicals}

Unless otherwise stated, all reagents were of the highest purity grade available and were purchased from Sigma (Milano, Italy).

\section{Animals}

Male Wistar rats (250-300g) (HarlanNossan, Corezzana, MB, Italy), 11-12 week old obese ( $f a / f a)(375 \pm 15 \mathrm{~g})$ and lean $(f a /+)$ $(300 \pm 10$ g) male ZR (Charles River, Calco, LC, Italy) were used. The animals were allowed free access to water and food in all the experiments. The use and care of animals in this experimental study was approved by the Italian Ministry of Health and by the University Commission for Animal Care. Rats were anesthetized with sodium pentobarbital $(40 \mathrm{mg} / \mathrm{kg}$ i.p.) and received $250 \mathrm{U}$ of heparin via the inferior vena cava before liver uptake.

Small tissue blocks of about $0.5 \mathrm{~cm}^{3}$ were cut, then inserted in cryovials and snap-frozen immediately in liquid nitrogen. Afterwards, the material was kept at $-80^{\circ} \mathrm{C}$ until further use. Cryostat sections, $8 \mu \mathrm{m}$ thick, were cut at $-24^{\circ} \mathrm{C}$ on a Leica CM 1850 cryostat.

\section{Demonstration of alkaline phosphatase activity}

The indoxyl-tetrazolium salt method ${ }^{35,36}$ utilizes a tissue protectant, the polyvinyl alcohol (PVA), in order to improve the localization of the coloured product in the exact zone in which the enzyme is present. Sections $8 \mu \mathrm{m}$ thick were cut on a manually-driven Leica CM 1850 cryostat at a cabinet temperature of $-25^{\circ} \mathrm{C}$. The sections were picked up onto clean glass slides and stored at $-80^{\circ} \mathrm{C}$ until used.

After a 5 min drying at room temperature, the cryosections were incubated with a medium containing 18\% PVA dissolved in $100 \mathrm{mM}$ Tris-HCl buffer (pH 9.0), $0.7 \mathrm{mM} \mathrm{5-bromo-4-}$ chloro-3-indolyl phosphate, $0.44 \mathrm{mM} \mathrm{1-}$ methoxy-phenazine methosulphate (mPMS), $10 \mathrm{mM} \mathrm{MgCl}_{2}, 5 \mathrm{mM}$ sodium azide and $5 \mathrm{mM}$ tetranitroblue tetrazolium (TNBT), previously dissolved in a heated mixture of dimethylformamide and ethanol (1:1, v/v), since it is not possible to dissolve $5 \mathrm{mM}$ TNBT in aqueous media. The final concentration of these solvents in the incubation medium was $2 \%$. Incubation lasted $20 \mathrm{~min}$ at $37^{\circ} \mathrm{C}$. To stop the reaction and to remove the incubation medium the sections were rinsed with hot $\left(45-50^{\circ} \mathrm{C}\right)$ tap water and the slide mounted with glycerine-jelly. Control sections were performed in the absence of substrate.

\section{Morphology}

Samples of the liver of obese rats were quickly removed, and all small fragments were fixed by immersion in $2.5 \%$ glutaraldehyde in $0.13 \mathrm{M}$ Millonig buffer $(\mathrm{pH} 7.2-7.4)$ at $4^{\circ} \mathrm{C}$ for $4 \mathrm{~h}$, rinsed, post-fixed with $1 \%$ osmium tetroxide at $4^{\circ} \mathrm{C}$ for $2 \mathrm{~h}$, washed, dehydrated through graded concentrations of alcohol, and embedded in Epon. Semi-thin sections ( $1 \mu$ m thick) were stained with $1 \%$ toluidine blue.

\section{Microscopy and photomicrography}

The slides were observed with Zeiss Axioskop 2 Plus light microscope (Carl Zeiss Microimaging, Jena, Germany) equipped with differential interference contrast (DIC) system and a Olympus C-4040 Zoom digital camera (Olympus, Tokyo, Japan) with 4 Mpixel of resolution. Digital images were elaborated with Adobe Photoshop 5 (Adobe Systems Inc., San José, CA, USA) and processed with Image Pro Plus 4.7 image analysis software (Media Cybernetics, Inc., Bethesda, MD, USA). A selective discrimination based on colour level was performed in order to highlight with false colour the distribution pattern of AlkP.

\section{Results}

With the indoxyl-tetrazolium salt method, the activity of AlkP is demonstrated by a dark brown final reaction product. A light brown diffuse staining was also observed in the controls lacking the substrate, therefore corresponding to non-specific reaction usually mentioned as nothing dehydrogenase reaction $(\mathrm{NDH}){ }^{37}$

\section{Wistar rat liver}

In Wistar rats (Figure 1), an irregular but strong staining was present in bile canaliculi, especially in the periportal region but also in the mid-zone (Figure 1a and 1b); a light diffuse staining was seen the cytoplasm of portal hepatocytes. Small bile ducts and Hering canals were intensely coloured, but large intralobular bile ducts, whose morphology is clearly delineated by DIC, were negative (Figure 1a, 1c and 1d). In Hering canals the reaction was cytoplasmic whereas in small bile ducts it was located mainly in the apical and lateral membrane domains (Figure 1c). Reaction was also seen in the adventitia of large arteries, but not of small ones (Figure 1a).

\section{Lean Zucker rat liver}

Respect to Wistar rat liver, differences in reactivity were noticed only in hepatocytes (Figure 2). Namely, staining was less intense and present not only in bile canaliculi but also 
in the basolateral membrane domains (Figure 2 a,b,c). As in Wistar rat liver, the AlkP activity was very strong in bile ductules but negative in larger bile ducts (Figure 2a).

\section{Obese Zucker rat liver}

In small and large bile ducts the AlkP distribution pattern in this animal model of obesity was similar to that seen in lean ZR and Wistar rats (Figure $3 \mathrm{a}$ and inset). Marked differences were observed in hepatocytes. In particular, hepatocytes in the periportal area were negative whereas macrosteatotic hepatocytes in the mid-zone displayed intense staining in canaliculi and moderate staining in basolateral membrane domains (Figure $3 \mathrm{~b}$ ). The mid-zone was furthermore characterized by moderately intense NDH reaction. The typical morphology of macro-and microsteatotic hepatocytes is shown in Figure 3c.

A better appraisal of the differences in subcellular distribution of AlkP activity in hepatocytes of Wistar, lean and obese ZR liver is shown in Figure $3 \mathrm{~d}$-f, where the most intense levels of AlkP are evidenced by a blue false colour by means of image analysis.

\section{Discussion}

The biliary tree, considered the Achilles' heel of liver transplantation ${ }^{9}$ is morphologically and functionally heterogeneous. ${ }^{38,39}$ The primary bile is secreted by hepatocytes into bile canaliculi, which drain into canals of Hering at the ductular-hepatocellular junction, lined in part by hepatocytes and in part by cholangiocytes. In the rat, Hering canals are in direct flow with small bile ducts (lined by cuboidal cells) that in turn empty into large bile ducts (lined by columnar cells). ${ }^{38,40}$ Cholangiocytes play an important role in water and electrolyte secretion, modulating canalicular bile through a sequence of both secretory and absorptive processes aimed at adjusting bile flow and alkalinity to the physiological needs. . $^{38,39}$

Three mechanisms contributing to bile duct injury after liver transplantation have been postulated: injury due to preservation or ischemia/reperfusion, immunological processes and injury induced by cytotoxicity of biliary bile salts. ${ }^{11,14,18}$ Bile salts are potent detergents that may damage cells by affecting the integrity of cellular membranes, in particular by extracting phospholipids and cholesterol from membranes to form micelles. ${ }^{41}$ Normally, these toxic effects are prevented by neutralization of bile salts by phospholipids and the formation of mixed micelles in bile. Phospholipids are secreted into bile in human via the concerted action of canalicular multidrug resistance-3 (MDR3) P-glycoprotein and canalicular bile salts. ${ }^{17}$

Steatotic liver, increasingly frequent among potential liver grafts for 0LT, is often discarded, since its response to conventional cold storage is very poor. ${ }^{3}$ Our group has recently developed an alternative preservation modality, based on machine perfusion at subnormother- mic temperature $\left(20^{\circ} \mathrm{C}\right.$; MP20) that has revealed a high potential for the preservation of normal and fatty livers. ${ }^{27,28,42}$ Besides investigating with a histochemical approach various parameters related to the metabolism and injury of parenchymal and sinusoidal cells of livers submitted to MP20 28,29 we sought to doc-
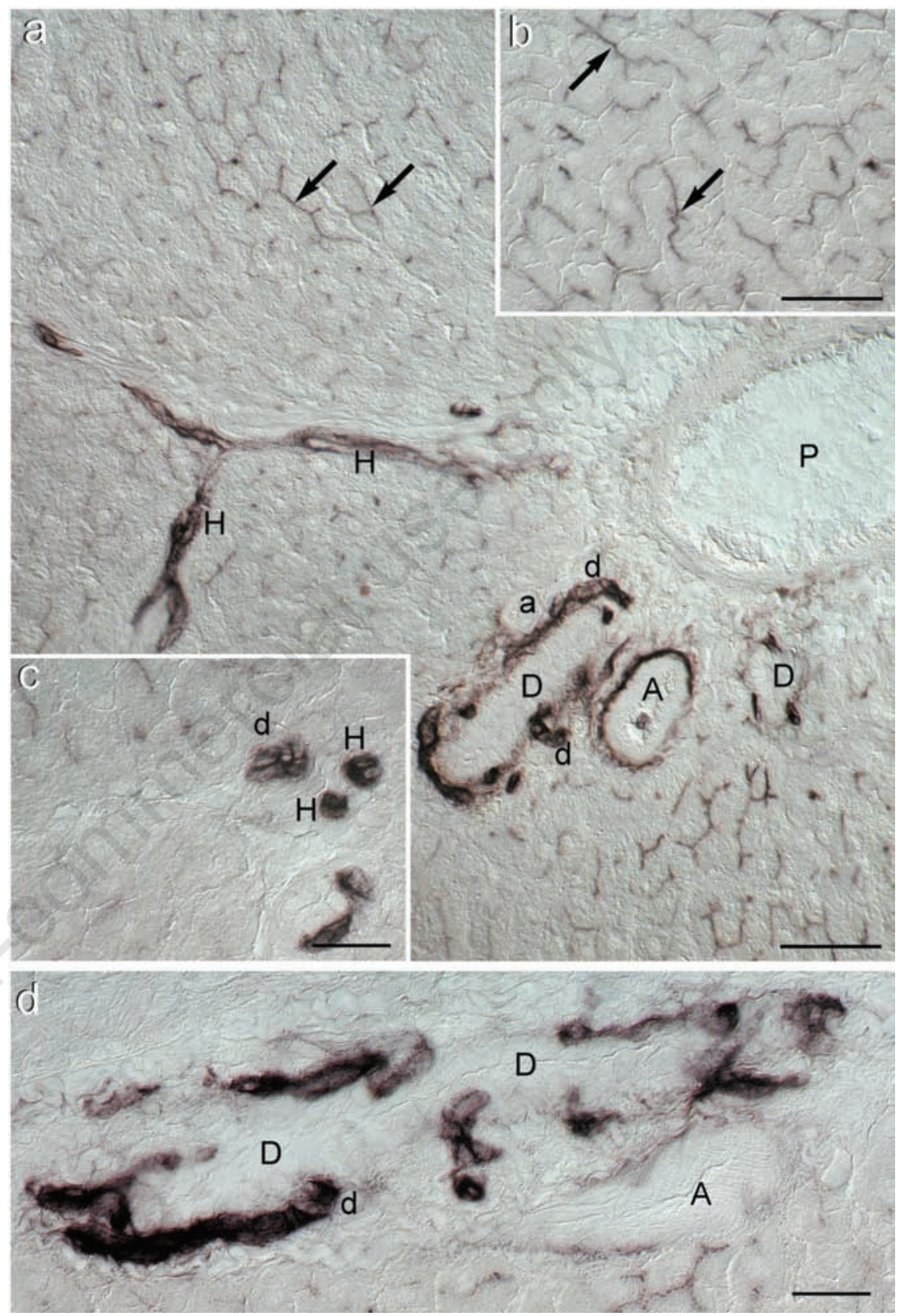

Figure 1. Photomicrographs of histochemical demonstration of alkaline phosphatase activity in Wistar rat liver (differential interference contrast; DIC); (a) Survey view of the portal area. The reaction is very intense in small bile ducts $(d)$, Hering's canals $(H)$, tunica externa (adventitia) of large arteries (A) but not in arteriole (a) and in several bile canaliculi identified mostly longitudinally but also transversally (black arrows). In the lumen of one of the large arteries a positive granulocyte can be seen. P: portal vein branch. Scale bar = $50 \mu \mathrm{m}$; (b) Typical chicken-wire pattern of bile canaliculi (black arrows) in the portal area (see also Figure 3d). Scale bar $=50 \mu \mathrm{m}$; (c) Detail of AlkP activity in bile ductule $(d)$ and Hering's canals $(H)$ seen under higher magnification. Scale bar $=25 \mu \mathrm{m}$; (d) Closer view of bile ductule (d) confluence into a larger bile duct (D) Scale bar $=25 \mu \mathrm{m}$. 
ument the response of the biliary tree using the most frequently used functional marker of biliary structures and integrity, alkaline phosphatase. Since no data were available we made a preliminary study, here reported, to describe its distribution and activity in fatty liver, taking normal Wistar rat liver and lean ZR liver as controls.

\section{Wistar rat liver}

The distribution of AlkP in Wistar rat liver is in keeping with the histochemical literature on the enzyme, independently of the method used for its visualization, that is the indoxyltetrazolium salt method used in the present research, ${ }^{35,43,44}$ the metal capture method or the simultaneous coupling method..$^{36,37,45}$ However, as far as large bile ducts are concerned, our data disagree with data reported on reviews, ${ }^{38,46}$ according to which in the rat AlkP is expressed by large interlobular bile ducts but not by small bile ducts. In particular, a research showing that exogenous alkaline phosphatase was able to inhibit secretin-stimulated ductal secretion by blocking cystic fibrosis transmembrane regulator (CFTR) channels expressed only in large ducts, ${ }^{47}$ was said to be

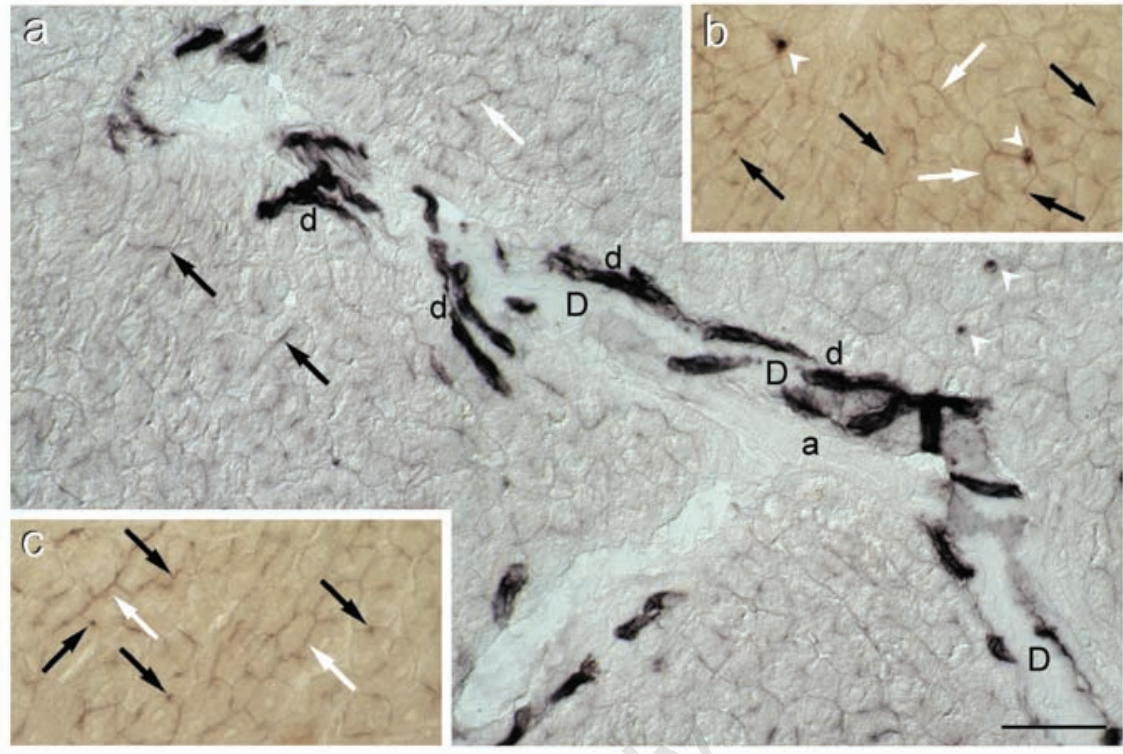

Figure 2. Alkaline phosphatase activity in lean Zucker rat liver. (a) Survey of a portal region showing several intensely stained bile ductules (d) which abut into on a large duct (D), negative for AlkP. Moderately intense staining is present not only in bile canaliculi (black arrows) but also in basolateral (interhepatocyte) membrane domains (white arrows). The white arrow heads indicate positive sinusoidal cells. (a)=arteriole. (DIC); (b) and (c) Details of AlkP staining in interhepatocyte membrane domains (white arrows) and bile canaliculi (black arrows) (bright field) (see also Figure 3e). Scale bar $=50 \mu \mathrm{m}$.
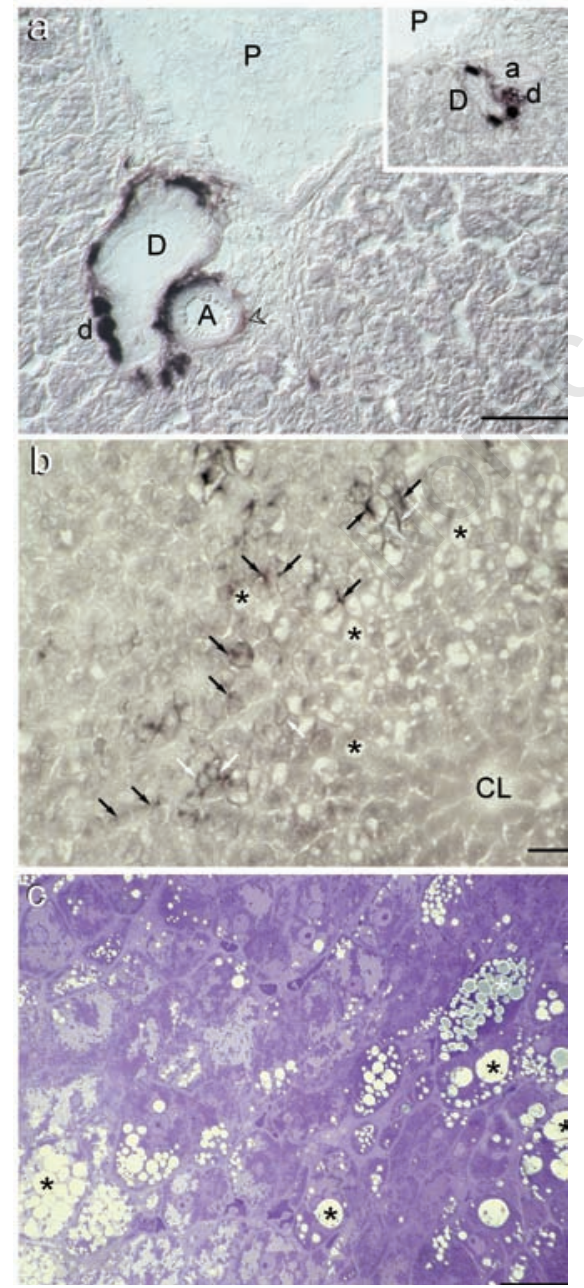
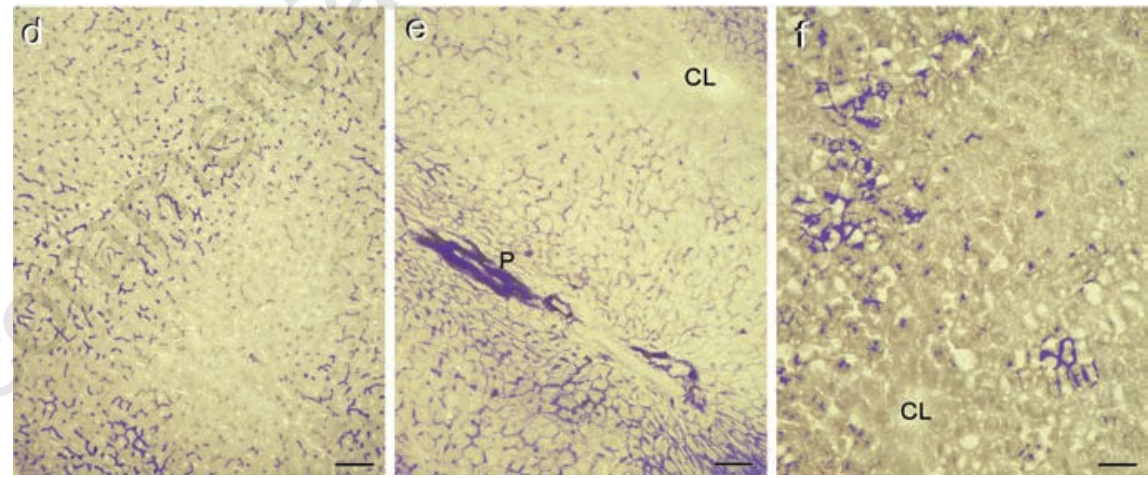

Figure 3. Alkaline phosphatase activity in obese Zucker rat liver and comparison among the highest levels of AlkP activity in Wistar, lean and obese Zucker rat hepatocytes. (a) Detail of a portal region of obese Zucker rat liver showing a strong reaction in bile ductules (d) confluent on a negative large bile duct (D) (see also inset). Hepatocytes are negative for the AlkP reaction. A: large artery (the void arrow head indicates fibroblasts in the adventitia, moderately positive for the reaction); a: small artery; P: branch of portal vein. DIC. Scale bar $=\mathbf{5 0}$ um; (b) Detail of a macrosteatotic area of obese Zucker rat liver (black asterisks) in the midzone characterized by strong AlkP reaction in canalicular (black arrows) and less intense staining in basolateral domains (white arrows); elsewhere the reaction in hepatocytes is negative (see also Figure 3f. CL: centrolobular vein. Bright field. Scale bar $=50 \mu \mathrm{m}$; (c) Representative light photograph of a semithin section of obese Zucker rat stained with Toluidine Blue. Both microsteatotic (white asterisks) and macrosteatotic (black asterisks) hepatocytes can be identified; the bluish color of droplets indicates the presence of unsaturated lipids (fixed by osmium tetroxide) whereas most unstained small droplets contained saturated fat, that having not being fixed by osmium tetroxide has been extracted during the inclusion process. Unsaturated lipid is thus abundant in macrosteatotic cells. Bright field. Scale bar = $25 \mu \mathrm{m}$; (d) Wistar rat liver: Intense canalicular AlkP activity, highlighted in blue, is present in hepatocytes in the periportal and mid-zone regions. Bright field and image analysis. Scale bar $=25 \mu \mathrm{m}$; (e) Lean Zucker rat liver: the reaction is seen both in interhepatocyte and canalicular domains in the periportal area and mid-zone. A small bile duct with intense activity parallel to a branch of the portal vein $(\mathrm{P})$ is also evidenced. CL: centrolobular vein. Scale bar $=25 \mu \mathrm{m}$; (f) Obese Zucker rat liver: Macrosteatotic hepatocytes in the midzone region show intense AlkP activity, in canalicular and interhepatocyte domains. CL: centrolobular vein. Scale bar $=25 \mu \mathrm{m}$. 
in keeping with the expression of AlkP in large but not small ducts. ${ }^{46}$ However, Alvaro et al., ${ }^{47}$ who used the same enzyme histochemical method we did, reported AlkP activity along bile canaliculi in the periportal region and in cholangiocytes, without mentioning which ducts and showing a photograph at low magnification, where the morphology of the stained bile structures cannot be evaluated. On the other hand, and as demonstrated herein, the observation of sections from all the three animal models under differential interference contrast never showed AlkP activity in cholangiocytes nor in the lumen of large ducts, but only in bile ductules and Hering canals. We suggest that what could be interpreted by Alvaro et al., ${ }^{47}$ as basal activity in large ducts when sections were observed under bright field and low magnification, was in reality the reaction present in small bile ducts or Hering canals that form a marked plexus around the portal canal. ${ }^{48}$ The best choice for analysing unstained structures is indeed DIC.

Staining for AlkP activity of the adventitia of large arteries is in accordance with observations made on rat myocardium with the metal capture method and with antibodies against rat liver AlkP. ${ }^{49}$ The absence of staining in the sinusoidal endothelial cells has as well been reported before. ${ }^{50}$ It is worth recalling that whereas human liver AlkP activity occurs in the sinusoid and, to a lesser extent, biliary pole of hepatocytes,$^{51}$ in rat liver activity is mainly localized in the canalicular membrane of hepatocytes and in portal triad blood vessels. ${ }^{52}$

\section{Lean Zucker rat liver}

Respect to Wistar rat liver, a significant difference in intracellular AlkP activity in lean Zucker rat liver was seen in hepatocytes, whereas similar patterns and reaction intensity were seen in the other segments of the biliary tree. As a matter of fact, hepatocytes in lean ZR displayed AlkP activity not only in bile canaliculi but also (though less intense respect to obese rat liver) in basolateral membrane domains.

\section{Obese Zucker rat liver}

Respect to Wistar and lean ZR, in the obese rat liver the differences of AlkP activity were once more seen only at the hepatocyte level. In fatty liver, portal hepatocytes were negative whereas the most steatotic cells in the midzone had intense lateral membrane staining and only occasionally canalicular activity, distorted by fat droplets.

In order to correlate the differences in AlkP activity in hepatocytes to metabolic features of the three animal models it would have been helpful to know the physiological role of AlkP and the nature of its natural substrate in hepa- tocytes and cholangiocytes. Unfortunately, these remain controversial, although AlkP has been routinely applied as a marker for liver function for over 70 years. ${ }^{37,53,54}$ In particular, the function and role of AlkP in the progression of cholestatic diseases are virtually unknown. ${ }^{47}$

In the following we review and discuss several alternative proposals for AlkP function.

\section{Phosphorylcholine hydrolysis}

Pekarthy et al. ${ }^{55}$ suggested that at least one of the functions of canalicular AlkP in hepatocytes was to hydrolyze phosphorylcholine so that choline could be transported across the bile canalicular membrane; this hypothesis was later questioned by studies showing that purified rat liver alkaline phosphatase had no particular affinity for phosphorylcholine and that it could act instead in general as a nonspecific ATPase. ${ }^{31}$ However, the speculation that AlkP might be involved in choline transport across cell membranes is still being put forth. ${ }^{56}$ This hypothesis could be relevant for the turnover of biliary phosphatidyl choline that may be degraded in bile by phospholipase $\mathrm{C}$ to phosphorylcholine and diacylglycerol. ${ }^{57} \mathrm{By}$ catalysing the subsequent removal of phosphate from phosphorylcholine, alkaline phosphatase of hepatocytes would contribute to reabsorption of choline from bile. ${ }^{58}$ To our knowledge, no choline reabsorption in bile ducts has been reported.

Choline is an essential nutrient needed for the structural integrity and signaling functions of cell membranes; for normal cholinergic neurotransmission; for normal muscle function; for lipid transport from liver; it is the major source of methyl groups in the diet, a choline deprived diet may induce steatosis of the liver and eventually cause hepatocarcinogenesis. ${ }^{59}$ As far as membranes are concerned, choline is required for the biosynthesis of phosphatidylcholine, sphingomyelin and choline plasmalogens. The concentration of sphingomyelin is higher in the canalicular domain of hepatocytes plasma membrane respect to the sinusoidal domain. ${ }^{60}$ Within the canalicular domain, sphingolipids are particularly concentrated in lipid rafts. ${ }^{61}$ Plasmalogens have a relatively low concentration in the liver, but are known to be present mainly associated to sphingolipids in lipid rafts. ${ }^{62}$

\section{Non-specific ectonucleotidases}

Earlier studies suggested that AlkP might act as an ecto-phosphatase regulating extracellular concentrations of phosphate compounds such as pyridoxal-5'-phosphate (the cofactor form of vitamin B6), phosphoethanolamine ${ }^{63}$ and some phosphoproteins. ${ }^{64}$

Other researches suggested that AlkP might play an important role in the modulation of purinergic signalling, that is, that of an ectonucleotidase capable of degrading extracellular ATP (or its derivatives ADP and AMP) to adenosine. ${ }^{31,47,65-67}$ Alkaline phosphatases remove phosphate groups in the 5' and 3' positions from several types of molecules including nucleotides. ${ }^{66}$ Extracellular nucleotides and, in particular, ATP, act as important autocrine/ paracrine signalling molecules regulating hepatobiliary functions such as hepatocyte glycogen metabolism, cell volume, bile formation, and other cell functions. These effects are mediated by the activation of purinergic receptors. Hepatocytes release ATP in venous blood and in the bile, and cholangiocytes secrete ATP in the bile. ${ }^{68}$ Purinergic receptors have been identified in the plasma membrane of hepatocytes and cholangiocytes; their activation contributes to the regulation of metabolism, ion channel activation, coordination within the liver lobule of cell-to-cell $\mathrm{Ca}^{2+}$ signalling, cell volume regulation, secretion, and coupling of the separate hepatocyte and cholangiocyte contributions to bile formation. ${ }^{68,69}$ Nucleotides released in the extracellular space are rapidly inactivated by ectonucleotidases. ${ }^{70}$ Each liver cell type expresses its own repertoire of purinoceptor subtypes and ecto-ATPases. ${ }^{66,71}$ Immunohistochemical studies of ecto ATP diphosphohydrolase (nucleoside triphosphate diphosphohydrolase) performed on pig liver showed strong reactivity in the bile canaliculi of hepatocytes (especially in the periportal region) in bile ducts, in the endothelium of the portal vein and in smooth muscle cells in the portal artery wall. ${ }^{72}$ This topological distribution colocalizes with the distribution of AlkP activity observed in the Wistar rat liver

\section{Ecto- protein phosphatase}

Ecto-phosphatase is still another putative function for alkaline phosphatase. ${ }^{53,54}$ AlkP, being anchored to the plasma membrane, could dephosphorylate soluble cellular substrates, or cell surface proteins. Ectokinases were shown to phosphorylate both soluble substrates and membrane-bound proteins.$^{73}$ These processes were though to regulate ligand binding, signal transduction and cell-to-cell interations. Both protein kinases and phosphatases are thought to be required for reversible control of extracellular phosphorylation processes acting in a manner similar to that in which they control cytoplasmatic phosphorylationdephosphorylation systems. ${ }^{53,74-76}$ The physiological function of AlkP as an ecto-phosphatase remains controversial, mainly because early studies with purified AlkP describe the enzyme as exhibiting a non-physiological alkaline $\mathrm{pH}$ optimum. ${ }^{77}$ However, a pH optimum of 7-8 was determined for purified and plasma membrane-bound human liver AlkP. ${ }^{53,64}$ It must be 
recalled that, although the main control of bile alkalinization is performed by cholangiocytes, ${ }^{78}$ bicarbonate secretion takes place already at canalicular level ${ }^{79}$ and thus that the bile $\mathrm{pH}$ is compatible with AlkP activity.

The multidrug resistance-1 (MDR1) P-glycoprotein (ABCB1; ATP-binding Cassette transporter) that transports cationic and neutral compounds and steroids out of cells ${ }^{80,81}$ was specifically investigated as a possible target of the above mentioned ectophosphorylationdephosphorylation processes. ${ }^{54,82-85}$ MDR1/Pglycoprotein/ABCB1 has been reported in bile canaliculi throughout the lobule ${ }^{46,79,85,86}$ and in the apical pole of cholangiocytes. ${ }^{46,80,86,87}$ Membrane-bound AlkP concentration in different tissues was shown to be positively correlated with the extent of exchange surface per unit volume of the tissue, suggesting an association between AlkP and transport systems. ${ }^{88}$ AlkP is located in close association with transporters that play a major role in the process of bile formation both in hepatocytes and cholangiocytes. ${ }^{47}$ P-glycoprotein modulators were shown to significantly affect the activity of hepatic-AlkP and thus the two processes seem to be metabolically coupled. ${ }^{54}$

\section{Modulation of endotoxin toxicity}

A further and physiologically completely different role proposed for AlkP is defence mechanism against endotoxin toxicity. ${ }^{66}$ Indeed human placental alkaline phosphatase (HPLAP) attenuates the lipopolysaccharide (LPS)-mediated inflammatory response, likely through dephosphorylation of the lipid A moiety of LPS. ${ }^{33,89}$ This role could contribute to the defence of the biliary tract against sepsis.

The above reviewed diversified functions proposed for AlkP might not be incompatible, but instead refer to different anatomic locations within the biliary tree.

\section{Discussion of histochemical patterns in terms of the putative functions of alkaline phosphatase}

The non-specific light staining (NDH) is ascribed to lactate dehydrogenase activity acting on endogenous lactate and nicotinamide dinucleotide $\left(\mathrm{NAD}^{+}\right)$and/or to endogenous thiol groups of glutathione, cysteine and other tissue proteins. ${ }^{37}$ The higher levels of NDH observed in the liver of obese ZR respect to Wistar and lean ZR are in keeping with higher lactate dehydrogenase activity observed in the former (unpublished study) and with data indicating higher concentration of lactate in the liver of obese ZR respect to their lean controls. ${ }^{90}$

The different behaviour of hepatocytes of lean ZR respect to Wistar rats, and in particular, the basolateral reactivity, similar to that observed in macrosteatotic hepatocytes of obese rats, might be a consequence of the fact that lean ZR are phenotypically normal but genotypically heterozygous for a recessive mutated allele.

The distribution of AlkP in hepatocytes of the steatotic liver of obese rats was markedly different from that of normal liver. The absence of canalicular enzyme activity in most hepatocytes suggests a substantial decrease in choline reabsorption and/or decreased modulation of purinergic signaling, and/or modulation of the activity of extracellular kinases. As a matter of fact, a marked reduction of bile saltdependent and bile salt-independent bile secretion with significant functional and molecular alterations consistent with mild cholestasis were reported in obese ZR, respect to lean animals. ${ }^{24,41,91,92}$ In particular was decreased the expression of some hepatocyte transporters such as the basolateral organic anion transporting polypeptide-2 (OATP2) ${ }^{80}$ and the canalicular multidrug resistance-associated protein 2 (MRP2/ABCC2). ${ }^{79,91,92}$ The conclusion of these papers, based exclusively on biochemical determinations, was that a defective hepatobiliary transport capacity could contribute to the higher susceptibility of obese ZR to liver injury. To our knowledge, no study has correlated AlkP activity to the activity of these transporters. Further important characteristics of the liver of obese ZR are compromised microcirculation that reduces the organ oxygenation $^{93}$ and energy balance (low [ATP/ADP]) with decreased mitochondrial activity respect to lean animals. ${ }^{90} \mathrm{~A}$ lower energy charge and glycogen content of obese ZR liver respect to lean ZR was also reported by our group. ${ }^{28}$ Therefore, ATP-dependent transport across the canalicular membrane might be impaired due to low ATP available.

The intense AlkP activity patterns in basolateral membrane domains in macrosteatotic hepatocytes are typical of cholestasis and were presumed to indicate the formation of extracanalicular sites for bile salt transport out of the hepatocytes in conditions where bile secretion is hindered..$^{94,95}$ In cholestasis, a strong upregulation of apical MDR1/ABCB1 was reported, as a presumed defence reaction against toxic metabolites. ${ }^{85,96,97}$

In conclusion, the absence of AlkP activity in the canaliculi of hepatocytes of obese Zucker rat liver indicates an impairment of processes related to primary bile formation, extracellular signalling modulation and/or choline reabsorption. By contrast, the processes mediated by AlkP in bile ductules and ducts are apparently not modified in these animals respect to normal ones. As lean ZR are concerned, the AlkP patterns, different from those of normal Wistar rats and are more similar to the patterns of obese rats, suggest that the functioning of their liver is not normal.

Alkaline phosphatase activity had been initially selected as a possible marker of the whole biliary tree response to the stresses endured by the fatty liver during the various phases of transplantation. This study demonstrates that it might be used only for documenting damage bile ducts.

\section{References}

1. Marsman H, Matsushita T, Dierkhising R, Kremers W, Rosen C, Burgart L, et al. Assessment of donor liver steatosis: pathologist or automated software? Hum Pathol 2004;35:430-5.

2. Nocito A, El-Badry AM, Clavien PA. When is steatosis too much for transplantation? Journal of Hepatology 2006;45:494-9.

3. Dutkowski P, de Rougemont 0, Clavien PA. Machine perfusion for 'marginal' liver grafts. Am J Transplant 2008; 8:917-924.

4. Sun B, Jiang HC, Piao DX, Qiao HQ, Zhang L. Effects of cold preservation and warm reperfusion on rat fatty liver. World $\mathrm{J}$ Gastroenterol 2000; 6:271-4.

5. Busuttil RW, Tanaka K. The utility of marginal donors in liver transplantation. Liver Transpl 2003; 9:651-63.

6. Angulo P. Nonalcoholic fatty liver disease and liver transplantation. Liver Transpl 2006; 12:523-34.

7. Xu C, Yu C, Li Y. Current studies on therapeutic approaches for ischemia/reperfusion injury in steatotic livers. Hepatol Res 2008; 38:851-9.

8. Angele MK, Rentsch M, Hartl WH, Wittmann B, Graeb C, Jauch KW, et al. Effect of graft steatosis on liver function and organ survival after liver transplantation. Am J Surg 2008;195:214-20.

9. Krom RA, Sanchez-Urdazpal L. The biliary tree--the Achilles tendon of liver preservation? Transplantation 1992;53:1167

10. Koneru B, Sterling MJ, Bahramipour PF. Bile Duct Strictures After Liver Transplantation: A Changing Landscape of the Achilles' Heel. Liver Transpl 2006;12: 702-4.

11. Buis CI, Hoekstra H, Verdonk RC, Porte RJ. Causes and consequences of ischemictype biliary lesions after liver transplantation. J Hepatobiliary Pancreat Surg 2006; 13:517-24.

12. Hübscher SG, Portmann BC. Transplantation Pathology. In: MacSween RNM, Burt AD, Portmann BC, Ishak KG, Scheuer PJ and Anthony PP (eds.) Pathology of the Liver. 2002, Churchill Livingstone, Edinburgh, UK, pp. 885-941.

13. Jagannath S, Kalloo AN. Biliary complica- 
tions after liver transplantation. Curr Treat Options Gastroenterol 2002;5:101-12.

14. Buis CI, Geuken E, Visser DS, Kuipers F, Haagsma EB, Verkade HJ, et al. Altered bile composition after liver transplantation is associated with the development of nonanastomotic biliary strictures. J Hepatol 2009;50:69-79.

15. Lenzen R, Bähr A, Eichstädt H, Marschall $\mathrm{U}$, Bechstein W0, Neuhaus P. In liver transplantation, $\mathrm{T}$ tube bile represents total bile flow: physiological and scintigraphic studies on biliary secretion of organic anions. Liver Transpl Surg 1999; 5:8-15.

16. Vajdova K, Smrekova R, Kukan M, Lutterova M, Wsolova L. Bile analysis as a tool for assessing integrity of biliary epithelial cells after cold ischemia-reperfusion of rat livers. Cryobiology 2000;41:145-52.

17. Hoekstra H, Porte RJ, Tian Y, Jochum W, Stieger B, Moritz W, et al. Bile salt toxicity aggravates cold ischemic injury of bile ducts after liver transplantation in MDR2+/- mice. Hepatology 2006;43:102231.

18. Geuken E, Visser D, Kuipers F, Blokzijl H, Leuvenink HG, de Jong KP, et al. Rapid increase of bile salt secretion is associated with bile duct injury after human liver transplantation. J Hepatol 2004;41:101725.

19. Cutrin JC, Cantino D, Biasi F, Chiarpotto E, Salizzoni M, Andorno E, et al. Reperfusion damage to the bile canaliculi in transplanted human liver. Hepatology 1996;24:1053-7.

20. Kukan M, Haddad PS. Role of hepatocytes and bile duct cells in preservation/ reperfusion injury of liver grafts. Liver Transplant 2001; 7:381-400.

21. Testa G, Malagò M, Broelseh CE. Complications of biliary tract in liver transplantation. World J Surg 2001;25: 1296-9.

22. Verdonk RC, Buis CI, Porte RJ, van der Jagt EJ, Limburg AJ, van den Berg AP, et al. Anastomotic biliary strictures after liver transplantation: causes and consequences. Liver Transpl 2006;12:726-35.

23. Seifalian AM, Piasecki C, Agarwal A, Davidson BR. The effect of graded steatosis on flow in the hepatic parenchymal microcirculation. Transplantation 1999;68: 780-4.

24. Koteish A, Diehl AM. Animal models of steatosis. Semin Liver Dis 2001;21:89-104.

25. Sun CK, Zhang XY, Zimmermann A, Wheatley AM. The metabolic and microcirculatory impact of orthotopic liver transplantation on the obese Zucker rat. Transplantation 2003;75:761-9.
26. Devlin TN. Textbook of Biochemistry with Clinical Correlations. 1997, Wiley-Liss, New York,NY, USA.

27. Vairetti M, Ferrigno A, Rizzo V, Boncompagni E, Carraro A, Gringeri E, et al. Correlation between the liver temperature employed during machine perfusion and reperfusion damage: role of $\mathrm{Ca} 2+$. Liver Transpl 2008;14:494-503.

28. Vairetti M, Ferrigno A, Carlucci F, Tabucchi A, Rizzo V, Boncompagni E, et al. Subnormothermic machine perfusion protects steatotic livers against preservation injury: a potential for donor pool increase? Liver Transpl 2009;15:20-9.

29. Boncompagni E, Ferrigno A, Milanesi G, Rizzo V, Carlucci F, Tabucchi A, et al. Improved preservation of fatty liver by machine perfusion at $20^{\circ} \mathrm{C}$ respect to conventional cold storage: biochemical, histochemical and ultrastructural approaches. Digest Liver Dis 2007;39:A10.

30. Boncompagni E, Gini E, Ferrigno A, Milanesi G, Barni S, Cillo U, et al. Machine perfusion of fatty livers at $20^{\circ}$ reduces sinusoidal cell and hepatocyte apoptosis respect to conventional cold storage. Digest Liver Dis 2009;41:A21-A22.

31. Ohkubo A, Langerman N, Kaplan MM. Rat liver alkaline phosphatase. Purification and properties. J Biol Chem 1974; 249:7174-80.

32. Hatoff DE, Hardison WG. Bile acid-dependent secretion of alkaline phosphatase in rat bile. Hepatology 1982;4:433-9.

33. Poelstra K, Bakker WW, Klok PA, Hardonk MJ, Meijer DK. A physiologic function for alkaline phosphatase: endotoxin detoxification. Lab Investig 1997;76:319-27.

34. Kanno N, LeSage G, Glaser S, Alpini G. Regulation of cholangiocyte bicarbonate secretion. Am J Physiol Gastrointest Liver Physiol 2001;281:G612-25.

35. Van Noorden CJF, Jonges GN. Quantification of the histochemical reaction for alkaline phosphatase activity using the indoxil-tetranitro BT method. Histochem J 1987;19:94-102.

36. Van Noorden CJF, Frederiks WM. Enzyme Histochemistry. A Laboratory Manual of Current Methods, 1992. Oxford Science Publ., Oxford, UK.

37. Stoward PJ, Pearse AGE. Histochemistry: Volume III. 4th ed.,1991. Churchill Livingston, Edimburgh, UK.

38. Kanno N, LeSage G, Glaser S, Alvaro D, Alpini G. Functional heterogeneity of the intrahepatic biliary epithelium. Hepatology 2000;31:555-561.

39. Strazzabosco M, Fabris L. Functional anatomy of normal bile ducts. Anat Rec (Hoboken) 2008;291:653-60.

40. Alpini G, Phillips J, La Russo N. The biolo- gy of biliary epithelia. In: Arias IM, Boyer JL, Fausto N, Jakoby WB, Schachter D and Shafritz DA (eds.). The Liver: Biology and Pathobiology, 3rd ed. 1994, Raven Press Ltd., New York, NY, USA, pp. 623-653.

41. VanPatten S, Ranginani N, Shefer S, Nguyen LB, Rossetti L, Cohen DE. Impaired biliary lipid secretion in obese Zucker rats: leptin promotes hepatic cholesterol clearance. Am J Physiol Gastrointest Liver Physiol 2001;281:G393404.

42. Ferrigno A, Carlucci F, Tabucchi A, Tommassini V, Rizzo V, Richelmi P, et al. Different susceptibility of liver grafts from lean and obese Zucker rats to preservation injury. Cryobiology 2009;59:327-34.

43. Van Noorden CJF, Vogels IM, Houtkooper JM. Cytophotometric analysis of alkaline phosphatase and 5'-nucleotidase activity in regenerating rat liver after partial hepatectomy. Cell Biochem Funct 1988;6:53-60.

44. Frederiks WM, Bosch KS. Quantitative aspects of enzyme histochemistry on sections of freeze-substituted glycol methacrylate-embedded rat liver. Histochemistry 1993; 100:297-302.

45. Lojda Z, Gossrau R, Schiebler TH. Enzyme Histochemistry. 1979, Springer-Verlag, Berlin, Germany.

46. Marzioni M, Glaser SS, Francis H, Phinizy JL, LeSage G, Alpini G. Functional heterogeneity of cholangiocytes. Semin Liver Dis 2002;22:227-40.

47. Alvaro D, Benedetti A, Marucci L, Delle Monache M, Monterubbianesi M, Di Cosimo E, et al. The function of Alkaline Phosphatase in the liver: Regulation of Intrahepatic Biliary Epithelium Secretory Activities in the rat. Hepatology 2000;32: 174-84.

48. Murakami T, Sato H, Nakatani S, Taguchi T, Ohtsuka A. Biliary tract of the rat as observed by scanning electron microscopy of cast samples. Arch Histol Cytol 2001;64: 439-47.

49. Schultz-Hector S, Balz K, Böhm M, Ikehara Y, Rieke L. Cellular localization of endothelial alkaline phosphatase reaction product and enzyme protein in the myocardium. $\mathbf{J}$ Histochem Cytochem 1993;41:1813-21.

50. Zoellner HFA, Hunter N. Histochemical identification of the vascular endothelial isoenzyme of alkaline phosphatase. J Histochem Cytochem 1989;37:1893-8.

51. Hägerstrand I. Distribution of alkaline phosphatase activity in healthy and diseased human liver tissue. Acta Pathol Microbiol Scand A 1975;83:519-26.

52. Hatoff DE, Toyota N, Wong C, Miller AL, Takeya M, Miyai K. Rat liver alkaline phosphatases. Evidence hepatocyte and portal triad enzymes differ. Dig Dis Sci 
1985;30:564-72.

53. Calhau C, Martel F, Pinheiro-Silva S, Pinheiro H, Soares-da-Silva P, HipólitoReis C, Azevedo I. Modulation of insulin transport in rat brain microvessel endothelial cells by an ecto-phosphatase activity. J Cell Biochem 2002;84:389-400.

54. Calhau C, Martel F, Hipólito-Reis C, Azevedo I. Effect of P-glycoprotein modulators on alkaline phosphatase activity in cultured rat hepatocytes. Cell Physiol Biochem 2000; 10:195-202.

55. Pekarthy JM, Short J, Lansing AI, Lieberman I. Function and control of liver alkaline phosphatase. J Biol Chem 1972; 247:1767-74.

56. Fernandez NJ, Kidney BA. Alkaline phosphatase: beyond the liver. Vet Clin Pathol 2007;36:223-33.

57. Pattinson NR, Willis KE. Phospholipase C and diacylglycerol lipase in human gallbladder and hepatic bile. Gastroenterology 1990;99:1798-806.

58. Kwon Y, Lee RD, Morris ME. Hepatic uptake of choline in rat liver basolateral and canalicular membrane vesicle preparations. J Pharmacol Exp Ther. 1996;279:774-81.

59. Zeisel SH. Choline: critical role during fetal development and dietary requirements in adults. Annu Rev Nutr 2006;26:229-50.

60. Schachter D. The hepatocyte plasma membrane. Organization and Differentiation. In: Arias IM, Boyer JL, Fausto N, Jacoby WB, Schachter D and Shafritz DA (eds.) The Liver. Biology and Pathobiology. 3rd ed. 1994, Raven Press, New York, NY, USA, pp. 145-154.

61. Tuma Pl, Hubbard AL. The hepatocyte surface: dynamic polarity. In: Arias IM, Boyer JL, Fausto N, Jakoby WB, Schachter D, Shafritz DA (eds.) The Liver. Biology and Pathobiology. 4th ed. 2001, Lippincott, Williams and Wilkins, Philadelphia, PA, USA, pp. 97-117.

62. Brites P, Waterham HR, Wanders RJA. Functions and biosynthesis of plasmalogens in health and disease. Biochimica et Biophysica Acta 2004;1636:219-31.

63. Whyte MP, Mahuren JD, Fedde KN, Cole FS, McCabe ER, Coburn SP. Perinatal hypophosphatasia: tissue levels of vitamin B6 are unremarkable despite markedly increased circulating concentrations of pyridoxal-5'-phosphate. Evidence for an ectoenzyme role for tissue-nonspecific alkaline phosphatase. J Clin Invest 1988; 81:1234-9.

64. Chan JRA, Stinson RA. Dephosphorylation of phosphoproteins of human liver plasma membranes by endogenous and purified liver alkaline phosphatases. J Biol Chem

\section{6;261:7635-9.}

65. Ohkubo S, Kimura J, Matsuoka I. Ectoalkaline phosphatase in NG108-15 cells: a key enzyme mediating P1 antagonist-sensitive ATP response. $\mathrm{Br} \mathrm{J}$ Pharmacol 2000;131:1667-172.

66. Beldi G, Enjyoji K, Wu Y, Miller L, Banz Y, Sun $\mathrm{X}$, et al. The role of purinergic signaling in the liver and in transplantation: effects of extracellular nucleotides on hepatic graft vascular injury, rejection and metabolism. Front Biosci 2008;13:2588603.

67. Beuers U, Hohenester S, de Buy Wenniger LJ, Kremer AE, Jansen PL, Elferink RP. The biliary $\mathrm{HCO}(3)(-)$ umbrella: a unifying hypothesis on pathogenetic and therapeutic aspects of fibrosing cholangiopathies. Hepatology 2010;52:1489-96.

68. Feranchak AP, Fitz JG. Adenosine triphosphate release and purinergic regulation of cholangiocyte transport. Semin Liver Dis 2002;22:251-62.

69. Feranchak AP, Lewis MA, Kresge C, Sathe M, Bugde A, Luby-Phelps K, et al. Initiation of purinergic signaling by exocytosis of ATP-containing vesicles in liver epithelium. J Biol Chem 2010;285:8138-47.

70. Zimmermann H. Two novel families of ectonucleotidases: molecular structures, catalytic properties and a search for function. Trends Pharmacol Sci 1999;20:231-6.

71. Fausther M, Lecka J, Kukulski F, Lévesque SA, Pelletier J, Zimmermann H, et al. Cloning, purification, and identification of the liver canalicular ecto-ATPase as NTPDase8. Am J Physiol Gastrointest Liver Physiol 2007;292:G785-95.

72. Leclerc MC, Grondin G, Gendron FP, Sévigny J, Beaudoin AR. Identification, characterization, and immunolocalization of a nucleoside triphosphate diphosphohydrolase in pig liver. Arch Biochem Biophys 2000; 377:372-8.

73. Redegeld FA, Caldwell CC, Sitkovsky MV. Ectoprotein kinases: ecto-domain phosphorrylation as a novel target for pharmacological manipulation? Trends Pharmacol Sci 1999;20:453-9.

74. Becq F, Fanjul M, Merten M, Figarella C, Hollande E, Gola M. Possible regulation of CFTR-chloride channels by membranebound phosphatases in pancreatic duct cells. FEBS Lett 1993;327:337-42.

75. Becq F, Jensen TJ, Chang XB, Savoia A, Rommens JM, Tsui LC, et al. Phosphatase inhibitors activate normal and defective CFTR chloride channels. Proc Natl Acad Sci USA 1994;91:9160-4.

76. Martins MJ, Negrão MR, Hipólito-Reis C. Alkaline phosphatase from rat liver and kidney is differentially modulated. Clin Biochem 2001;34:463-8.
77. McComb RB, Bowers GN, Posen J, Posen S. Alkaline phosphatase. 1979, Plenum Press, New York, NY, USA.

78. Strazzabosco M. Transport systems in cholangiocytes: their role in bile formation and cholestasis. Yale J Biol Med 1997;70: 427-34.

79. Ujházy P, Kipp H, Misra S, Wakabayashi Y, Arias IM. The biology of the bile canaliculus. In: Arias IM, Boyer JL, Fausto N, Jakoby WB, Schachter D and Shafritz DA (eds.) The Liver. Biology and Pathobiology. 4th ed. 2001, Lippincott, Williams and Wilkins, Philadelphia, PA, USA, pp. 361372.

80. Arrese M, Accatino L. From blood to bile: recent advances hepatobiliary transport. Ann Hepatol 2002;1:64-71.

81. Jonker JW, Stedman CA, Liddle C, Downes M. Hepatobiliary ABC transporters: physiology, regulation and implications for disease. Front Biosci 2009;14:4904-20.

82. Martel F, Martins MJ, Hipólito-Reis C, Azevedo I. Inward transport of [3H]-1phenylpyridinium in rat isolated hepatocytes: putative involvement of a P-glycoprotein transporter. Br J Pharmacol 1996; 119:1519-24.

83. Martel F, Calhau C, Martins MJ, Azevedo I. Uptake of $3 \mathrm{H}$-adrenaline by freshly isolated rat hepatocytes: putative involvement of P-glycoprotein. J Auton Pharmacol 1998; 18:57-64.

84. Martel F, Calhau C, Hipólito-Reis C. Effect of bile duct obstruction on hepatic uptake of 1-methyl-4-phenylpyridinium in the rat. Pharmacol Res 1998;37:497-504.

85. Ros JE, Libbrecht L, Geuken M, Jansen PL, Roskams TA. High expression of MDR1, MRP1, and MRP3 in the hepatic progenitor cell compartment and hepatocytes in severe human liver disease. J Pathol 2003;200:553-60.

86. Vander Borght S, Libbrecht L, Blokzijl H, Faber KN, Moshage H, Aerts R, et al. Diagnostic and pathogenetic implications of the expression of hepatic transporters in focal lesions occurring in normal liver. $\mathrm{J}$ Pathol 2005;207:471-82.

87. Lazaridis KN, Strazzabosco M, Larusso NF. The cholangiopathies: disorders of biliary epithelia. Gastroenterology 2004; 27:156577.

88. Calhau C, Hipólito-Reis C, Azevedo I. Alkaline phosphatase and exchange surfaces. Clin Biochem 1999; 32:153-4.

89. Poelstra K, Bakker WW, Klok PA, Kamps JA, Hardonk MJ, Meijer DK. Dephosphorylation of endotoxin by alkaline phosphatase in vivo. Am J Pathol 1997;151: $1163-9$.

90. Serkova NJ, Jackman M, Brown JL, Liu T, Hirose R, Roberts JP, et al. Metabolic pro- 
filing of livers and blood from obese Zucker rats. J Hepatol 2006;44:956-62.

91. Pizarro M, Balasubramaniyan N, Solís N, Solar A, Duarte I, Miquel JF, et al. Bile secretory function in the obese Zucker rat: evidence of cholestasis and altered canalicular transport function. Gut 2004;53:1837-43.

92. Geier A, Dietrich CG, Grote T, Beuers U, Prüfer T, Fraunberger $\mathrm{P}$, et al. Characterization of organic anion transporter regulation, glutathione metabolism and bile formation in the obese Zucker rat. J Hepatol 2005;43:1021-30.
93. Ijaz S, Yang W, Winslet MC, Seifalian AM. Impairment of hepatic microcirculation in fatty liver. Microcirculation 2003;10:44756.

94. Frederiks WM, Van Noorden CJF, Aronson DC, Marx F, Bosch KS, Jonges GN, et al. Quantitative changes in acid phosphatase, alkaline phosphatase and 5'nucleotidase activity in rat liver after experimentally induced cholestasis. Liver 1990;10:158-66.

95. Aronson DC, Chamuleau RA, Frederiks WM, Gooszen HG, Heijmans HS, James J. Reversibility of cholestatic changes fol- lowing experimental common bile duct obstruction: fact or fantasy? J Hepatol 1993;18:85-95.

96. Zoellner G, Fickert P, Zenz R, Fuchsbichler A, Stumptner C, Kenner L, et al. Hepatobiliary transporter expression in percutaneous liver biopsies of patients with cholestatic liver diseases. Hepatology 2001;33:633-46.

97. Zoellner G, Fickert P, Silbert D, Fuchsbichler A, Marschall HU, Zatloukal $\mathrm{K}$, et al. Adaptive changes in hepatobiliary transporter expression in primary biliary cirrhosis. J Hepatol 2003;38:717-27. 